\title{
Why We Have to Teach Scientific Ethics in the Oceanography Classroom
}

BY MATTHIAS TOMCZAK

How many of the students you face in your lectures will become environmental consultants? How many may at some stage during their career be required to evaluate an environmental impact statement (EIS)? How many will be expected to express a scientifically founded opinion on environmental issues?

The answers should be obvious to all of us. Very few students of the marine sciences embark on a professional consulting career. A similarly small number will enter positions in government authorities and find themselves in a position to make judgements on consultancy reports. A slightly larger number can expect to be approached by the media for their opinion on controversial issues. Future teachers and lecturers will influence their students by the way in which they present ocean science. Both teachers and students will become public ambassadors for the value of science to society.

It follows from that analysis that teaching a scientific topic is not just a question of presenting facts about the natural world; it is also an introduction into the way we make use of scientific knowledge. This aspect of teaching has taken on a greater importance in today's world because changes in government structures have created a situation that makes it easier for scientifically questionable procedures to slip through unnoticed.

When the first wave of environmental protests in the 1960s and 1970s caused governments to introduce environmental legislation and establish environmental protection agencies, a new class of government employees was entrusted with the task of verifying that new development proposals were not environmentally hazardous. These government "bureaucrats" were scientifically trained and often undertook research on the government's behalf. Where they "outsourced" an EIS they had the scientific background to verify that the methods used in the EIS were adequate for the task.

In today's world, governments favor privatization. Environmental work is often put out for tender, generally to the same people who ten years ago had been government employees and who are now supporting their families as private consultants. As a consequence, the scientific expertise of government departments has virtually disappeared, and the people who are evaluating the submitted tenders often do not understand the tender details and allocate projects solely on price.

When a contest is no longer judged on the basis of scientific merit, the temptation is large to submit a low-priced tender based on flawed methodology. I have seen situations where a government asked for circulation studies in highly stratified coastal waters with complicated coastline topography and accepted a tender based on a two-dimensional vertically integrated numerical model simulation. Any reasonably well-trained oceanographer would know that such a model is inadequate for the situation. But commercial pressure combined with lack of government expertise to evaluate the proposed method can lead to a decision to ignore ethical issues and submit a low-priced proposal based on flawed methodology.

How do we as science teachers respond to this? In my own student days, a course on the history of science was

Matthias Tomczak (Matthias.Tomczak @flinders.edu.au) is Professor, Flinders University, Adelaide, Australia. 
part of the science curriculum. It did not always address questions of scientific ethics specifically, but at the very least it conveyed the ethical dimension of science through the lives of great scientists. Financial pressure on science departments has resulted in the disappearance of such courses. As a result, questions of scientific ethics have to become part of everyone's teaching.

The implications can be formulated in two requirements. The first requirement is an increased appreciation of quantitative science over qualitative description. There will always be a need for taxonomy, physical geography of the sea, and other descriptive sciences, but in today's world an EPI is incomplete without a numerical model, and being able to appreciate the capabilities and shortcomings of numerical models is an essential requirement for any scientific evaluation. This is true not only for circulation grated vs. box models. Differences among these models can be appreciated by students having a minimal mathematical background and can be taught in forms adapted to the capabilities of the class. If this raises the general appreciation of the value of mathematics in science this will be a welcome additional result.

The second requirement is an appreciation of scientific ethics. The medical profession has defined ethical standards and penalties for those who violate them, including exclusion from the profession. The engineering profession has a code of ethics with established penalties. The Australian Computer Society announced last October its intention to introduce an accreditation system for technology professionals that will include a code of conduct. Environmental scientists do not have to be accredited members of a society and thus do not face punitive measures for shoddy work.

\section{...questions of scientific ethics have to become part of everyone's teaching.}

models of physical oceanography but for ecosystem models of all types as well.

Quantitative science means, of course, mathematics, so the first requirement can also be expressed as increased appreciation of mathematics. It would be unrealistic to demand a full mathematical education from every marine science student. A minimum requirement has to be some basic understanding of the advantages and limitations of different classes of models: implicit vs. explicit models, level vs. layer models, vertically inte-
Intentional use of inadequate methodology in environmental contracts is a case of scientific dishonesty. The standard procedure to prevent scientific dishonesty in academic research is the peer-review system of publications. The equivalent system in the commercial world used to be the tender evaluation process. All the signs are that this process does not fulfil that role any more. There are also indications that the peer-review process is under strain and in danger of falling apart when it comes to decisions about scientific ethics in environmental science. Last year the editor-in-chief and two of the co-editors of Climate Research resigned in protest over the handling of a paper by a co-editor and the decision of the publisher to let the paper go to print (Manton, 2003).

The case of Bjørn Lomborg, associate professor of statistics in the political science department of the University of Aarhus and director of the Danish Environmental Assessment Institute (20022004), is an illuminating example. In 2001, Cambridge University Press published his book The Skeptical Environmentalist: Measuring the Real State of the World. The book became a bestseller. The World Economic Forum named Lomborg a "Global Leader of Tomorrow." Business Week voted him one of the "50 Stars of Europe” (Dayton, 2003). According to "the official web page for Bjørn Lomborg" (http://www.lomborg.com/), the Skeptical Environmentalist "challenges widely held beliefs that the global environment is progressively getting worse. Using statistical information from internationally recognized research institutes, Lomborg systematically examines a range of major environmental issues and documents that the global environment has actually improved. He supports his argument with over 2900 footnotes, allowing discerning readers to check his sources."

In January 2003, the Danish Committee on Scientific Dishonesty, acting on various complaints, ruled that Lomborg's book is "clearly contrary to the standards of good scientific practice" and satisfies the criteria for "objective scientific dishonesty." Four months later, the Danish Ministry of Science, Technology 
and Innovation issued a statement that the Committee exceeded its statutory authority, and in December 2003 it pub- lish papers critical of the IPCC (Intergovernmental Panel on Climate Change) because this may indeed strengthen the time has come to resurrect the teaching of scientific ethics in the undergraduate classroom. It is not my role as colum-

\section{Intentional use of inadequate methodology in}

\section{environmental contracts is a case of scientific dishonesty.}

lished a detailed critique of the Committee's ruling and returned the case to the Committee for renewed assessment.

Why is it so difficult to decide on an issue of scientific ethics? Because much of environmental science is characterized by large margins of uncertainty. Modern science has long left the area of everyday experience. Ordinary people have no way of judging the truth of statements made about climate change. The public has to take scientific assessments of climate change on trust. Only scientists can judge whether a scientific statement is based on best professional practice or made with hidden intentions.

When our students leave university and turn into teachers, researchers, consultants, government bureaucrats, or wherever else their career takes them, the day will come when someone will ask them what the scientific position is on the ozone hole, global warming, the Kyoto Protocol, the protection of marine parks from drilling for oil, and many other issues. How they approach information found in Energy and Environment or other scientific journals will then depend to a large degree on how much they have heard about basic principles of scientific ethics. Sonja Boehmer-Christiansen, editor of Energy and Environment, says "I claim the right to pub- voice of the fossil fuel owners, employees and users, including the developing countries rich in fossil fuel resources" (Boehmer-Christiansen, 2004).

In 1987 the United Nations Environment Programme (UNEP) and the World Meteorological Organization (WMO) set up the IPCC as the mechanism to establish the best possible scientific response to the question of whether current industrial activity will lead to climate change. The IPCC is not infallible, and publishing research critical of the IPCC's findings is legitimate science. But Boehmer-Christiansen is not only critical of the IPCC's findings, she rejects the IPCC as an institution and accuses it of bias. In her view, what is acceptable as relevant to the question of climate change "is ultimately selected by a coalition of the climate policy community devoted to the Kyoto Protocol (governments), WMO devoted to meteorological research, the environmental lobby and, acting as their mouthpiece, the small IPCC leadership of government friendly science politicians" (BoehmerChristiansen, 2004).

Such arguments do not operate in the realm of scientific debate or controversy; they imply unethical behavior of the IPCC. When they are elevated to the editorial policy of a scientific journal, the nist of Oceanography to provide the appropriate curriculum for that; this has to be decided by each instructor in the classroom. One approach, which I have used over several years with reasonable success, consists of an evaluation of an imagined development for its environmental impact. The students are provided with field data and asked to describe the current state of the marine environment as well as its expected state if the development goes ahead. The analysis of their reports concentrates on the question of degree to which their scientific assessment is influenced by personal preference for a particular course of action.

Societies such as ours play an important role in upholding standards of professional ethics. The Oceanography Society may well think about what it can do to assist in this field. 四

\section{REFERENCES}

Boehmer-Christiansen, S. 2004. A response to "Summary of recent reports on climate change science" by Michael Manton. Bulletin of the Australian Meteorological and Oceanographic Society 17:42-45.

Dayton, L. 2003. The Bjorn storm. The Australian. 4 October 2003.

Manton, M. J. 2003. Summary of recent reports on climate change science. Bulletin of the Australian Meteorological and Oceanographic Society 16:130-135. 